\title{
Impact induced melting and the development of large igneous provinces
}

\author{
Adrian P. Jones ${ }^{\mathrm{a}, *}$, G. David Price ${ }^{\mathrm{a}}$, Neville J. Price ${ }^{\mathrm{a}}$, Paul S. DeCarli ${ }^{\mathrm{a}, \mathrm{b}}$, \\ Richard A. Clegg ${ }^{c}$ \\ a Department of Geological Sciences, University College London, Gower Street, London WC1E 6BT, UK \\ b SRI International, Menlo Park, CA 94025, USA \\ c Century Dynamics Ltd., Dynamics House, Hurst Road, Horsham, West Sussex RH12 2DT, UK
}

Received 20 February 2002; received in revised form 1 May 2002; accepted 5 July 2002

\begin{abstract}
We use hydrodynamic modelling combined with known data on mantle melting behaviour to examine the potential for decompression melting of lithosphere beneath a large terrestrial impact crater. This mechanism may generate sufficient quantity of melt to auto-obliterate the crater. Melting would initiate almost instantaneously, but the effects of such massive mantle melting may trigger long-lived mantle up-welling that could potentially resemble a mantle hotspot. Decompression melting is well understood; it is the main method advocated by geophysicists for melting on Earth, whether caused by thinned lithosphere or hot rising mantle plumes. The energy released is largely derived from gravitational energy and is outside (but additive to) the conventional calculations of impact modelling, where energy is derived solely from the kinetic energy of the impacting projectile, be it comet or asteroid. The empirical correlation between total melt volume and crater size will no longer apply, but instead there will be a discontinuity above some threshold size, depending primarily on the thermal structure of the lithosphere. We estimate that the volume of melt produced by a $20 \mathrm{~km}$ diameter iron impactor travelling at $10 \mathrm{~km} / \mathrm{s}$ may be comparable to the volume of melt characteristic of terrestrial large igneous provinces $\left(\sim 10^{6} \mathrm{~km}^{3}\right)$; similar melting of the mantle beneath an oceanic impact was also modelled by Roddy et al. [Int. J. Impact Eng. 5 (1987) 525]. The mantle melts will have plume-like geochemical signatures, and rapid mixing of melts from sub-horizontal sub-crater reservoirs is likely. Direct coupling between impacts and volcanism is therefore a real possibility that should be considered with respect to global stratigraphic events in the geological record. We suggest that the end-Permian Siberian Traps should be reconsidered as the result of a major impact at $\sim 250 \mathrm{Ma}$. Auto-obliteration by volcanism of all craters larger than $\sim 200 \mathrm{~km}$ would explain their anomalous absence on Earth compared with other terrestrial planets in the solar system. (C) 2002 Elsevier Science B.V. All rights reserved.
\end{abstract}

Keywords: large igneous provinces; impacts; melting; volcanism; hydrodynamics; simulation

\footnotetext{
* Corresponding author. Tel.: +44-207-679-7083; Fax: +44-207-387-1612.

E-mail addresses: adrian.jones@ucl.ac.uk (A.P. Jones), d.price@ucl.ac.uk (G.D. Price), pdecarli@unix.sri.com (P.S. DeCarli), richard.clegg@centurydynamics.co.uk (R.A. Clegg).
}

\section{Introduction}

Ever since the acceptance of the Huttonian principle of uniformitarianism, it has been difficult for Earth scientists to accept any explanation 
of a geological event that relies on a catastrophic mechanism. This problem is epitomised by the time that was taken to recognise the importance of meteoritic impacts in planetary evolution. Thus, even the origin of lunar craters was strongly debated until the middle part of the 20th century, and until the 1950s, geologists were reluctant to accept an impact origin for Meteor Crater (Arizona), which is arguably one of the best preserved of all terrestrial craters. Since then, the number of accepted terrestrial craters has risen at a rate of about 2-4 per year, and currently stands at $>150$, with no indication of a reduction in the rate of detection [2]. Furthermore, many of these impacts have now been accepted as having caused major geological and/or ecological events, such as the association of the Chicxulub event with the $\mathrm{K} / \mathrm{T}$ extinction and the impact origin for the Sudbury complex.

The recognition of a geological feature as having an impact origin generally rests on observing a number of characteristic shock-related effects in the country rock [3]. These may include, for example: (a) tektites, ejecta or pseudotachylite, (b) radial and ring faulting or uplift, (c) shock textures, shatter cones and high pressure minerals, (d) high concentrations of $\mathrm{Fe} / \mathrm{Ni} / \mathrm{S}$ and platinum group elements, or other geochemical signatures, (e) circular geophysical anomalies. However, it must be noted that the nature of the evidence for impact will depend on the details of the impact (size, velocity, composition, material properties and angle of impact of the impactor; and composition and material properties of the impacted region), as well as on the subsequent geological history of the impact site.

Some researchers, however, have gone beyond these accepted limits to suggest that several larger geological features had an impact origin, but have auto-obliterated the traditional evidence of impact by subsequent large-scale igneous activity. Examples of such suggestions include the Bushveld Complex [4], the Deccan Traps [5,6], the breakup of tectonic plates [7,8], and the formation of oceanic plateaus $[9,10]$ and continental flood basalts $[11,12]$. These suggestions have usually been rejected on the grounds that an impact model is less plausible than the widely accepted plume model [13]. The present paper is an attempt to demonstrate more rigorously the plausibility of an impact model for the initiation of a large-scale igneous event. Central to this paper is our contention that the phenomenon of pressure-release melting, or decompression melting, described in detail later, is the key to understanding the volumes of melt generated during large impacts and that in part this process has been overlooked or wrongly de-emphasised [14]. Melosh [15] contends that there is no firm evidence that impacts can induce volcanic activity in the impact crater region, and he presents strong arguments, based on the amount of energy available, against the proposal that an impact could trigger volcanism at a distance. He notes that suggestions of impactinduced volcanism have often been based on observations of the large basalt-filled basins on the lunar nearside, but these are undermined by the discovery of large unfilled far-side basins and by the evidence that nearside volcanism apparently post-dated basin formation by as much as $1 \mathrm{Ga}$. Melosh concluded that pressure-release melting was highly unlikely on the Moon and he discounted the possibility of pressure-release melting on the Earth. Recently, however, O'Hara [16] has countered these arguments, and points out that pressure-release melting will be important in any body if the geotherm is close to the solidus at some point beneath the crater. We support this argument and below outline indicative hydrodynamic simulations that suggest that a Sudburyscale impact crater $(\sim 200 \mathrm{~km}$ diameter crater $)$ would trigger instantaneous pressure-release melting if it occurred where geothermal gradients are high and the mantle temperature is already close to its solidus.

In this paper we will address these traditional objections to the impact-related origin of major igneous features, and will conclude that the plume hypothesis may not explain all of the features to which it is currently applied and that the previously suggested but generally dismissed mechanism of pressure-release melting does provide a mechanism for larger impacts to generate large volumes $\left(\sim 10^{6} \mathrm{~km}^{3}\right)$ of melt. We propose that a candidate large igneous province (LIP) generated by impact volcanism might be the Siberian Traps. 


\section{Large igneous provinces}

If one judges the degree of support for a hypothesis by the number who use the concept to explain their particular problem, then support for the plume origin for LIPs is endemic. There are two main hypotheses that have been proposed to explain the relationship between mantle plumes and flood basalts. In the plume-head hypothesis [17] Campbell and Griffiths consider that a large plume head, with a diameter of $\sim 1000 \mathrm{~km}$, originates at the core-mantle boundary and rises to form beneath the lithosphere an oblate circular disk, with a diameter of $\sim 2000 \mathrm{~km}$. This leads to an uplift of the overlying lithosphere of 0.5 $1.0 \mathrm{~km}$ and the development of volcanic activity. Plume-head melting occurs as the consequence of adiabatic decompression when the top of the plume reaches the top of the asthenosphere. Melting, they contend, will start at the hot leading edge of the top of the plume, where the plume can melt to produce high $\mathrm{MgO}$ magmas. As the plume head continues to rise and flatten, the cooler entrained mantle edge of the plume may start to melt if it experiences low pressures at shallow depths. In the second model, White and McKenzie [18] assumed a much smaller plume, with an unspecified origin. They emphasise that it is the production of melt material that is of paramount importance and note that the potential temperature of the plume need only be $100-300^{\circ} \mathrm{C}$ higher than the surrounding mantle. Only in the low-velocity zone (LVZ) are the $P$ and $T$ conditions such that the mantle is close to melting. As the increase in temperature caused by the plume is modest, the plume will only give rise to melting in a relatively narrow depth zone immediately beneath the LVZ. Consequently, they conclude that the depth of the stem of the plume is immaterial. But vital to their model is the coincident development of lithospheric thinning, which determines the volume of melt produced.

The debate over these and related approaches, including a wet plume model [19], has been vigorous. Although the role of plumes and hotspots in the development of volcanic chains such as Hawaii is not questioned, there are some, however, who question whether such plumes can be respon- sible for all large igneous provinces. Thus for example, Saunders et al. [20] maintain that the relatively short period between the initial contact, from below, to the generation of melt is likely to be less than $10 \mathrm{Ma}$. Despite the heat transfer that may take place between plume and continental lithosphere, they argue that large volumes of melt material are unlikely to be generated and even that the melt that occurs may freeze in situ as heat is lost to the lithosphere. Campbell and Griffiths [17] point out the shortcomings in the White and McKenzie hypothesis, while Anderson [21] questions both plume models, and suggests that more sources of geochemical anomalies and melting processes may occur instead at shallow depths in the mantle. Other authors suggest that detailed field evidence in some large igneous provinces does not support either model. Thus, in a recent review Sharma [22] observes; 'Collectively the [cited field] observations suggest that the Siberian Traps eruption cannot be linked directly either to lithospheric stretching in the absence of a plume or to hotspot initiation. Yet there appears to be consensus supporting a plume origin among those working on the Siberian Traps. Two pieces of evidence have engendered such a confluence of opinion: (i) the large volume $\left(>2 \times 10^{6} \mathrm{~km}^{3}\right)$ of magma emplaced and (ii) the short duration $\sim 1$ Ma of eruption.' Subsequent geological and geophysical papers have further undermined the possibility of a conventional mantle plume as the cause of the Siberian Traps [23,24].

In the following section, we indicate how decompression melting resulting from a large impact would generate large volumes of melt, which could be emplaced very rapidly, and might offer a more reasonable explanation for the Siberian Traps eruption, and perhaps other similar large igneous provinces, than the plume hypothesis.

\section{Impacts and decompression melting}

There is a well-established correlation between observed terrestrial crater size and the total volume of impact melt [14,25]. Melosh [14] points out that the volume of melt generated is based on calculations, as experiments are not able to 
access this high-energy regime. The simulations suggest that for terrestrial material a relationship between the ratio of the mass of melt $\left(m_{\text {melt }}\right)$ to the mass of the impactor ( $\left.m_{\text {impactor }}\right)$ is given by:

$m_{\text {melt }} / m_{\text {impactor }}=0.14 v^{2} / E_{\mathrm{m}}$ for $v>12 \mathrm{~km} / \mathrm{s}$

where $v$ is the velocity of the impactor and $E_{\mathrm{m}}$ is the latent heat of melting. This equation and scaling relationships lead Melosh to conclude that the melt mass would only exceed the mass displaced by the impact event for craters more than about $300 \mathrm{~km}$ in diameter.

Although possibly correct for gabbroic material at constant initial temperature (but see [26-29]), we believe that these relations do not scale, when applied to the Earth, where there is a lithospheric temperature gradient and the rocks at the base of the lithosphere are close to their melting temperature. Under these conditions, we expect that there would be a large degree of pressure-release melting as a result of the crater formation, which would produce much larger volumes of melt than would be predicted from simple kinetic energy considerations.

On Earth, remarkably small variations in crustal loading can yield substantial variations in the melting behaviour of underlying hot mantle, including, for example, a volcanic response to surface loading by relatively low-density glacial ice sheets. Thus, removal of glacial ice only $2 \mathrm{~km}$ thick (modelled as a disc of radius $180 \mathrm{~km}$ ) in Iceland would generate a predicted $30 \%$ increase in mantle melt productivity at depths of up to $\sim 100 \mathrm{~km}$ below the surface [30]. Such deglaciation-influenced mantle melting is consistent with detailed geochemical analyses of Icelandic volcanic rocks, with a time response of $\sim 1000 \mathrm{yr}$ and depths of melting down to $\sim 150 \mathrm{~km}$ [31]. Since impact craters modify crustal loading, it is inevitable that, where temperatures are sufficiently high in the underlying mantle, we can expect a wide variety of comparable decompression melting behaviour depending on crater size and morphology. Inversion of the Iceland deglaciation model [30] provides an important optimum case, which can be used as a one-dimensional guide to the minimum equivalent size of impact crater re- quired to cause the same effect. For $20 \mathrm{~km}$ thick Icelandic crust this equates to $\sim 3.5 \%$ of crustal mass, or a pressure reduction of just $\sim 0.03 \mathrm{GPa}$. The same effect could be produced by a shallow crater $0.67 \mathrm{~km}$ deep, but this ignores the dynamic process of crater formation.

Decompression melting has not been encountered in laboratory shock experiments, nor is it expected, since it is a phenomenon restricted to large-scale impacts. It is, however, well understood and is the main process advocated by geophysicists for melting on Earth. It is seen in mantle xenoliths rapidly decompressed by rising volcanic magmas [32] and can be simulated in sacrificial solid media experiments [33]. Partial melting of the mantle occurs wherever the ambient temperature exceeds the mantle solidus temperature. Under adiabatic conditions in the upper mantle this situation arises during uplift or decompression of hot mantle, since the melting temperature for mantle peridotite increases with pressure (positive $\mathrm{d} T / \mathrm{d} P$ ). The mantle potential temperature is the temperature that the mantle at depth would achieve if it were adiabatically brought to the surface; this must be further adjusted for the additional thermal loss associated with latent heat of melting. McKenzie and Bickle [34] correlated the total two-dimensional thickness of melt that can be extracted with the mantle potential temperature and degree of lithospheric thinning. Thus, the uniform thickness of oceanic crust $(\sim 7 \mathrm{~km})$ is consistent with the volume of melt produced if the mantle has a potential temperature of $\sim 1280^{\circ} \mathrm{C}$. We now consider how decompression melting may be induced by a large impact, where lithospheric thinning is effectively instantaneous, as required by McKenzie and Bickle [34].

Decompression melting of the mantle is effective because the temperature interval between ambient geotherm and lithological melting closes rapidly with increasing depth, so favouring melting on pressure release. By contrast, decompression of most crustal melts causes freezing, since these generally have negative melting curves at low pressures [35]. There is thus an increasing likelihood for decompression mantle melting with increasing transient crater depth $\left(H_{\mathrm{t}}\right)$, as the 


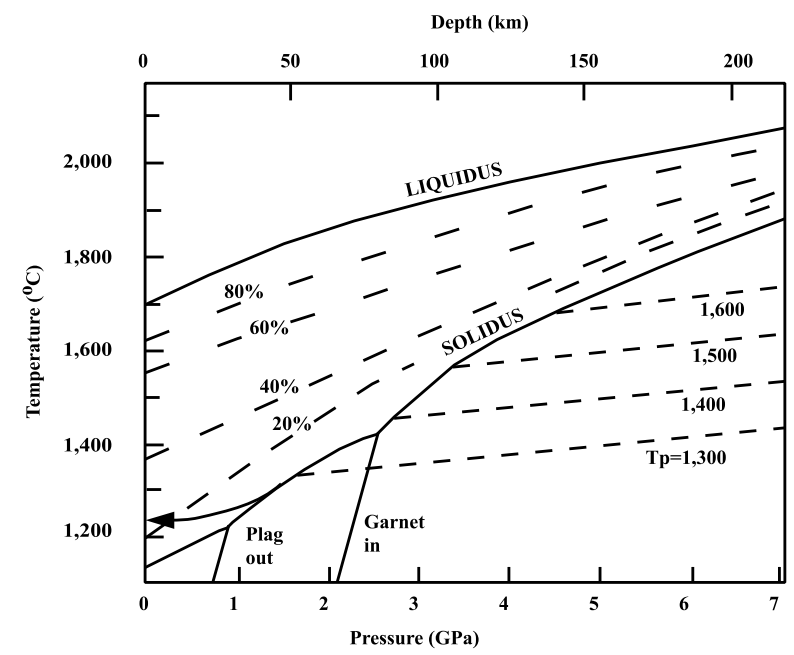

Fig. 1. Phase relations for mantle peridotite, showing degrees of melting at temperatures above the solidus, and curves for mantle potential temperatures in upper mantle peridotite (after [37]). The decompression trajectory for melting of mantle with a potential temperature of $1300^{\circ} \mathrm{C}$ is shown (deflected downwards by the latent heat of fusion: $\sim 450 \mathrm{~kJ} / \mathrm{kg}$ ). Melt compositions vary with the degree of melting and correspond to basalt ( $\sim 10-20 \%$ melting), picrite (up to $30 \%$ melting) and komatiite ( $>30-50 \%$ or more). A pressure decrease of $1.5 \mathrm{GPa}$ is similar to raising the temperature by up to $\sim 120^{\circ} \mathrm{C}$ and, in peridotite previously at solidus temperature, this leads to $\sim 25 \%$ melting.

weight of the overburden is reduced by crater excavation. Terrestrial geotherms are fixed at depths of approximately 410 and $660 \mathrm{~km}$ by the olivine to wadsleyite and ringwoodite to perovskite+magnesio-wustite phase transitions, respectively [36]. At much shallower depths, geotherms are superadiabatic and vary according to lithospheric structure. For oceanic lithosphere, geotherms vary with age from hot and young to cold and old. Geotherms for continental crust extend from the coolest gradients typical of stable cratons to those that overlap with lower oceanic values during active regional metamorphism (as at Sudbury).

The volume of decompression melt can be estimated by combining calculations of the pressure drop beneath an impact crater with mantle melting behaviour from published experimental data (as recently compiled by Thompson and Gibson [37]). For mantle peridotite the degree of partial melting is, to first order, related directly to the excess temperature above the solidus, for any given pressure. For example (Fig. 1), a pressure reduction of $15 \mathrm{kbar}(1.5 \mathrm{GPa})$ is equivalent to raising the temperature by up to $\sim 120^{\circ} \mathrm{C}$ and, in peridotite with a potential temperature of $1300^{\circ} \mathrm{C}$ previously on the solidus, leads to $\sim 25 \%$ melting. This simple observation is the crux of our argument, it represents an enormous potential for substantially melting the mantle beneath an impact crater and has profound consequences for the geological history of the Earth. Melt compositions will vary according to the degree of melting and correspond approximately to komatiite ( $>30-50 \%$ or more), picrite (up to $30 \%$ melting) and basalt (ca 10-20\% melting), respectively. Melting is not a kinetically hindered process because it is entropically so favourable, and so decompression melting will occur virtually instantaneously in hot mantle wherever there is sufficient reduction in pressure beneath a large impact, including reduction of lithostatic load by excavation of crater material, massive central uplift or lithostatic modification during formation of multi-ring structures.

To quantify the instantaneous stress drop resulting from impact crater formation, we have performed indicative hydrodynamic simulations using the AUTODYNE hydrocode described by Hayhurst and Clegg [38]. The AUTODYNE code 
Table 1

Details of the indicative hydrodynamic model used in this study

\begin{tabular}{ll}
\hline Code & AUTODYNE-2D version 4.1. \\
\hline Solver & $\begin{array}{l}\text { Smoothed particle hydrodynamics } \\
(22500 \text { particles })\end{array}$ \\
Target dimensions & $\begin{array}{l}600 \mathrm{~km} \times 300 \mathrm{~km} \\
\text { Target material }\end{array}$ \\
$\begin{array}{l}\text { Bast }- \text { SESAME EOS number } 7530, \\
\text { no strength model }\end{array}$ \\
$\begin{array}{l}\text { Iron }- \text { SESAME EOS number } 2410, \text { no } \\
\text { strength model; } 10 \mathrm{~km} \text { radius sphere, } \\
\text { initial velocity } 10 \mathrm{~km} / \mathrm{s}\end{array}$ \\
Nymmetry & Normal incidence, cylindrical symmetry \\
\hline
\end{tabular}

has been well validated by data from small-scale hypervelocity impact experiments with a variety of target and impactor materials [39]. In our simulation, the model parameters were not intended to represent in detail the full complexities of a real impact, but were chosen to illustrate the main principle of pressure variation during a large-scale global impact. The density and thermal effects of gravitational and shock compression were included in the simulation. Other details of the simulation are given in Table 1.

After $40 \mathrm{~s}$ the simulated transient crater has proportions of depth to diameter close to $1: 1$, which greatly exceeds the $1: 3$ ratio of conventional impact crater assumptions [14]; however, high aspect transient craters have been found in previous simulations. Thus, Roddy et al. [1], using a $10 \mathrm{~km}$ quartz, $10 \%$ porosity impactor at $10 \mathrm{~km} / \mathrm{s}$, find a maximum depth of $39 \mathrm{~km} \sim 30 \mathrm{~s}$ after impact, the diameter of the cavity is only $62 \mathrm{~km}$ (aspect ratio $\sim 1: 2$ ). Also, Pierazzo et al. [29] calculate for a similar impact (with $10 \mathrm{~km}$ dunite impactor moving at $20 \mathrm{~km} / \mathrm{s}$ at the same time after impact) a crater diameter of $\sim 60 \mathrm{~km}$ and depth of $\sim 35 \mathrm{~km}$ (aspect ratio again $\sim 1: 2$ ). The aspect ratio of the transient crater will depend on the details of the impact. Our calculations have a larger impactor-target density ratio (iron:basalt) than the simulations referred to above, and this led to the 1:1 depth-to-diameter ratio that we see.

The results for the simulation show that after $40 \mathrm{~s}$ there is a virtually spherical transient crater of $\sim 100 \mathrm{~km}$ diameter (Fig. 2), below which there is a clearly identified zone of depressurisation (i.e. $\left.P_{40}-P_{0}<0\right)$. There are two causes of decompression - one long-term, the other more transient. The latter is due to the rarefaction wave that immediately follows the compressive shock wave, which from Fig. 2 we calculate has a value of $\sim-2 \mathrm{GPa}$ at a depth of $\sim 220 \mathrm{~km}$ after $40 \mathrm{~s}$. At shallower depths, this rarefaction wave causes a large volume of mantle to have experienced super-solidus conditions for many seconds long enough for decompression melting to have initiated. A longer-lasting zone of decompression occurs directly beneath the crater produced by the excavation of the crater material and the resultant loss of lithostatic load. The amount of melting generated by these processes can be estimated by direct comparison of the decompression values calculated in the simulation (and shown as a snap shot after $40 \mathrm{~s}$ in Fig. 2) with the mantle melting relations shown in Fig. 1. Melting will occur virtually instantaneously over a range of depths during the course of the impact. We calculate that the integrated volume of rock to experience super-solidus conditions is $\sim 2 \times 10^{7} \mathrm{~km}^{3}$ during the course of the shock event. This leads to the production of $3 \times 10^{6} \mathrm{~km}^{3}$ of melt as the depressurised volume of mantle experiences an average of $15 \%$ partial melting. In a real impact event, the melt extraction process would be complicated by, for example, gravitational instability of newly formed low-density melts beneath the impact crater, melt viscosity, foundering of crustal rocks, variations in porosity and permeability in shattered rocks and explosive interaction with water. Withdrawal of a large volume of melt from the mantle, previously unsupported by, for example, a deep rising conventional plume, would, however, lead to further mass up-flow of the upper mantle during a secondary stage of dynamic flow or collapse into the vacated 'space' with resultant further melting [8]. For simplicity, we therefore assume delivery of only $\sim 30 \%$ of the melt to the surface [30]. Using the integrated results from our model we estimate that such an impact would yield $\sim 1 \times 10^{6} \mathrm{~km}^{3}$ of basaltic melt, comparable to the volume of the Siberian flood basalts. 


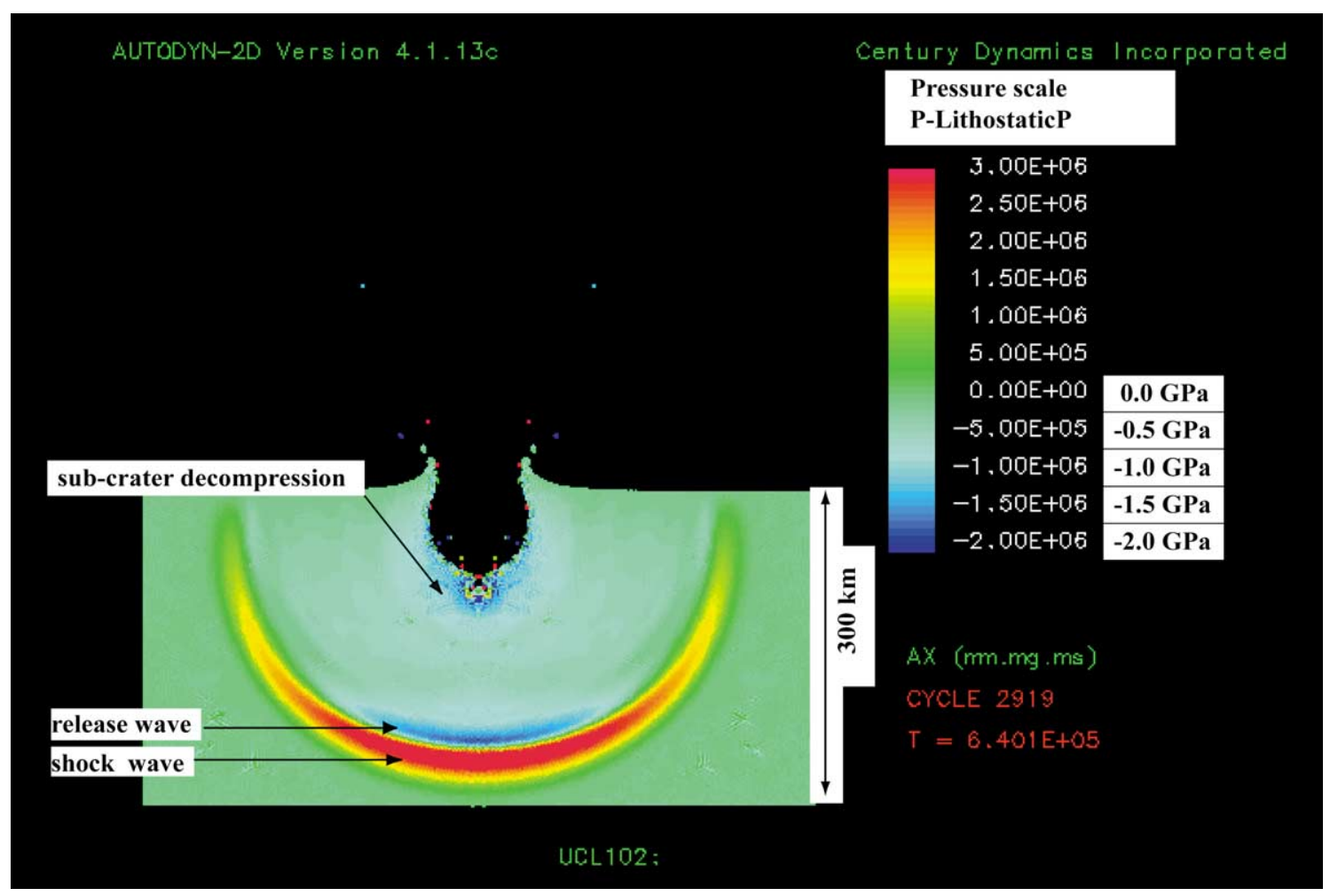

Fig. 2. Results of an indicative hydrocode model (AUTODYNE-2D) of a simulated impact designed to show regions where decompression melting should occur. The colour contours show the effective instantaneous pressure decrease (calculated as the difference between shock pressure and lithostatic load) $40 \mathrm{~s}$ after impact. The model shows a nearly spherical transient crater (diameter $\sim 100 \mathrm{~km})$. The high-pressure shock wave towards the base is shown in red. This model demonstrates three zones of decompression (blues): (a) a circum-crater zone with diameter approximately twice that of the crater and pressure drops of -1.5 to $-1.0 \mathrm{GPa}$; (b) a diffuse zone between (a) and (c) of lower $P$ contrast that extends over much of the intervening space (pressure drop 0 to $-1.0 \mathrm{GPa}$ ); and (c) a lower zone of negative pressure $(-2.0 \mathrm{GPa})$, immediately behind the high-pressure shock wave which will continue to follow the attenuating shock.

\section{Discussion and conclusions}

Having shown that a large impact could generate large volumes of melt, we need to consider whether the probability of this occurring is large enough to be significant in the Phanerozoic history of the Earth. Recent calculations imply formation of $>450$ terrestrial craters of $D>100 \mathrm{~km}$ since the late heavy bombardment, and cratering rate estimates suggest that a large $200 \mathrm{~km}$ crater may occur every $150 \mathrm{Ma}$ and a $500 \mathrm{~km}$ crater every $450 \mathrm{Ma}[40,41]$. Similar impact rates are implied independently by studies of comets and for the combined probabilities of comets and asteroids; Weissman [42] indicates that the impact probability of long-period comets large enough to produce craters $>10 \mathrm{~km}$ is about $1 \mathrm{Myr}^{-1}$ and estimates an interval of $1.7 \times 10^{7}$ yr between potentially catastrophic long-period comet impacts. Both comets and asteroids cause impacts, but comets can have much higher velocities [43]. If one assumes that this flux has remained constant since the end of the late heavy bombardment (at $\sim 3.8-4.0 \mathrm{Ga}$ ), then the derived flux is very similar to previous recent estimates [44]. There are perhaps $\sim 1000$ craters of diameter $>10 \mathrm{~km}$ 'missing' from the geological record in the last 3000 Ma. More significantly, the expected number of craters $>200 \mathrm{~km}$ diameter is $\sim 25$ and there should also be one to five craters of diameter 
$>500 \mathrm{~km}$; these have not yet been identified. Our contention is that the larger craters would have been auto-obliterated by impact volcanism and that they will appear very different to conventional craters.

We have yet to model the distribution and extraction of melts from beneath the crater floor in detail, but our indicative model develops saucershaped sub-horizontal sill-like bodies. This mimics conventional impact melts within craters except that these decompression melts are far below the crater itself. Melt extrusion would start with highly energetic eruption of low-viscosity peridotitic melts, which would be buoyant compared to the solid surrounding lithosphere. Interaction of these hot fluid melts with surface water would be likely to produce ultramafic and mafic pyroclastic rocks (as found in the Siberian Traps). Extraction of such large volumes of melt would lead to secondary mantle flow at ever decreasing rates due to increasing bulk viscosities with secondary melting and associated metasomatism. These regions of zoned partially molten mantle represent a massive thermal perturbation resembling a conventional hotspot and share a number of characteristics with mantle plumes. Such impact plumes (or 'I-plumes') could produce similar magmatic and geochemical signatures, but would differ from traditional hotspot plumes (or 'H-plumes') in that I-plumes neither require pre-magmatic thermal doming (see e.g. Siberian Traps) nor would they be related to a deep geophysical fingerprint. I-plumes may thus offer a possible alternative to H-plumes and would be linked to shallow enrichment and depletion events restricted to the upper mantle, as an alternative to the widely perceived involvement of the $\mathrm{D}^{\prime \prime}$ layer at the core-mantle boundary [37].

The Siberian Traps is the single largest eruption of 'continental' flood lavas and is dated exactly at the end of the Permian [45]. Up to one third of the lower succession is represented by pyroclastic rocks, with individual tuff units covering up to $30000 \mathrm{~km}^{2}$; they were initially marine and developed in a massive subsiding basin that rules out a conventional mantle plume [23]. Elkins-Tanton and Hager [24] endorsed Sharma's review [22] that the Siberian Traps cannot be the result of a traditional form of mantle plume. There is growing independent global evidence that an impact occurred at the P-Tr boundary. A weak Ir anomaly together with unmistakable shocked quartz were found both in Antarctica and Australia [46]. Accurate dating of Chinese strata at Meishan place the boundary at $251.4 \pm 0.3 \mathrm{Myr}$ and record catastrophic addition of isotopically light carbon over a time interval of $165000 \mathrm{yr}$ or less [47]. Subsequent investigation of the marine faunal extinction, including the same Meishan outcrops, lead Jin et al. [48] to conclude that 'a predicted true extinction level [occurred] near $251.3 \mathrm{Ma}$ (94\% of genera are included in a 0.1 -million-year (Myr) interval spacing). A more reasonable conclusion...is a sudden extinction at $251.4 \mathrm{Ma}$, followed by the gradual disappearance of a small number of surviving genera over the next 1 million years'. Finally an impact event is supported directly by evidence from extraterrestrial noble gases in fullerenes recovered from $\mathrm{P}-\mathrm{Tr}$ boundary beds in China, Japan and Hungary [49]. Recalling a close parallel with the evidence for bolide impact at the $\mathrm{K}-\mathrm{T}$ boundary [50], there is clearly a similar 'smoking gun' at the P-Tr boundary. Therefore, it would seem important to test our hypothesis that the Siberian Traps could have been caused by decompression melting at the impact site. The geological record may be consistent with this idea, but it appears that the critical volcanic-sedimentary interface has not yet been systematically mapped. However, the onset of volcanism is everywhere an unconformity marked by tuffs uniformly lying above folded and variably missing Palaeozoic strata [23]. The thickest volcanic sequence is in the northern part $(4000 \mathrm{~m}$, Maymecha-Kotuy; $3500 \mathrm{~m}$ Norilsk) where massive Ni-sulphide mineralisation is related to mantle-dissecting faults [51]. The large-scale occurrence of native nickel-iron [52] in intrusive rocks, related to the extrusive lavas, including Pt-bearing nickel-rich iron [53], is consistent with impact geochemical models which predict native iron [54] and is reminiscent of native iron at the base of the flood lavas in West Greenland [55]. Also, the regional geology of the wider Siberian craton and bounding mountain fold belts (Baikal, Verkhoyansky, Taymyr) should be recon- 
sidered in terms of the possible major plate-tectonic effects of an impact, as confirmed by changing plate vectors at $\sim 250 \mathrm{Ma}$ [8]. The large-scale foundering of continental Siberian lithosphere at this time, recently proposed on the basis of geophysical data [24], is consistent with our hypothesis. This hypothesis could explain the 'distinctive meteorite-like isotope geochemistry' [56] of the Siberian Traps and perhaps even the occurrence of cliftonite-bearing metallic nickel-iron in the intrusive traps [52] as direct relics of meteoritic iron. The current day Moho topography beneath Siberia is variable but segmented and has been interpreted as a series of mantle ridges and rifts [57]; seismic velocity structure shows a continuous substantial lateral velocity inversion $(8.0$ versus 8.4 $\mathrm{km} / \mathrm{s}$ ) at $\sim 100 \mathrm{~km}$ depth underlying the entire Siberian Platform [58]. All of these are consistent with being relict impact features, albeit on a larger scale than commonly observed.

In conclusion, we can only agree with the view of Boslough et al. [11], who stated 'the impactproduced flood basalt hypothesis is attractive because it is potentially testable on the basis of predictions of features that have not yet been discovered...unlike current plume models for flood basalts and hotspots'. To resolve this issue fully, further field work (e.g. [59]) and modelling is still required.

\section{Acknowledgements}

We thank Colin Hayhurst and others at Century Dynamics (UK) for support with the hydrocode modelling. A.P.J. and P.S.D. thank in particular Philippe Claeys for supporting initial ideas, and together with Christian Koeberl and the ESF IMPACT programme for providing excellent discussion meetings. We also thank John Brodholt, John Guest, Claudio Vita-Finzi, Francis Nimmo and other colleagues at UCL for comments, discussions and different points of view. This paper has also been greatly improved by helpful comments made by Jay Melosh and Lionel Wilson. $[\boldsymbol{B W}]$

\section{References}

[1] D.J. Roddy, S.H. Schuster, M. Rosenblatt, L.B. Grant, P.J. Hassig, K.N. Kreyenhagen, Computer simulations of large asteroid impacts into oceanic and continental sites preliminary results on atmospheric, cratering and ejecta dynamics, Int. J. Impact Eng. 5 (1987) 525-554.

[2] R.A.F. Grieve, in: M.M. Grady, R. Hutchinson, G.J. McCall, D.A. Rothery (Eds.), Meteorites: Flux with Time and Impact Effects, Geol. Soc. Spec. Publ. 140 (1998) 105.

[3] B.M. French, Traces of Catastrophe, Lunar and Planetary Institute, Houston, TX, Contribution 954 (1998) 120 pp.

[4] W. Hamilton, Bushveld complex - product of impacts? in: D.J.L. Vissler, G. Von Gruenewaldt (Eds.), Symposium on the Bushveld Igneous Complex and Other Layered Intrusions, Geol. Soc. S. Afr., Spec. Publ. 1 (1970) $367-$ 379.

[5] M.R. Rampino, Impact cratering and flood-basalt volcanism, Nature 327 (1987) 468-468.

[6] J.G. Negi, P.K. Agrawal, O.P. Pandey, A.P. Singh, A possible K-T boundary bolide impact site offshore Bombay and triggering of rapid Deccan volcanism, Phys. Earth Planet. Int. 76 (1993) 189-197.

[7] C.K. Seyfert, L.A. Sirkin, Earth History and Plate Tectonics, Harper and Row, New York, 1979, 96 pp.

[8] N.J. Price, Major Impacts and Plate Tectonics, Routledge, London, 2001, 416 pp.

[9] G.C. Rogers, Oceanic plateaus as meteorite impact signatures, Nature 299 (1982) 341-342.

[10] A.Y. Glikson, Oceanic mega-impacts and crustal evolution, Geology 27 (1999) 387-390.

[11] M.B. Boslough, E.P. Chael, T.G. Trucano, D.A. Crawford, D.I. Campbell, Axial focussing of impact energy in the Earth's interior: a possible link to flood basalts and hotspots, in: G. Ryder, D. Fastovsky, S. Gartner (Eds.), The Cretaceous-Tertiary Event and Other Catastrophes in Earth History, Geol. Soc. Am. Spec. Publ. 307 (1986) 541.

[12] V.R. Oberbeck, J.R. Marshall, H. Aggarwal, Impacts, tillites and the break-up of Gondwanaland, J. Geol. 101 (1993) 1-19.

[13] J.J. Mahoney, M.F. Coffin (Eds.), Large Igneous Provinces, Am. Geophys. Union, Geophys. Monogr. 100 (1997) $438 \mathrm{pp}$.

[14] H.J. Melosh, Impact Cratering - A Geological Process, Oxford Monogr. Geol. Geophys. 11 (1989) 245 pp.

[15] H.J. Melosh, Can impacts induce volcanic eruptions? in: Catastrophic Events and Mass Extinctions: Impacts and Beyond, Lunar and Planetary Institute, Houston, TX, Contrib. 1053 (2000) 141-142.

[16] M.J. O'Hara, Flood basalts, basalt floods or topless Bushvelds? Lunar petrogenesis revisited, J. Petrol. 41 (2000) 1545-1651.

[17] I.H. Campbell, R.W. Griffiths, Implications of mantle plume structure for the evolution of flood basalts, Earth Planet. Sci. Lett. 99 (1990) 79-83. 
[18] R. White, D.P. McKenzie, Magmatism of rift zones; the generation of volcanic continental margins and flood basalts, J. Geophys. Res. 94 (1989) 7685-7729.

[19] K. Gallagher, C.J. Hawkesworth, Dehydration melting and the generation of continental flood basalts, Nature 358 (1992) 57-59.

[20] A.D. Saunders, M. Storey, R. Kent, M. Norry, Consequences of plume-lithosphere interaction, in: Magmatism and the Causes of Continental Break-Up, Geol. Soc. Lond. Spec. Publ. 68 (1992) 41-60.

[21] D.L. Anderson, The EDGES of the mantle, in: The CoreMantle Boundary Region, Geodynamics 28, Am. Geophys. Union (1998) 255-271.

[22] M. Sharma, Siberian traps, in: J.J. Mahoney, M.F. Coffin (Eds.), Large Igneous Provinces: Continental, Oceanic and Planetary Flood Volcanism, Am. Geophys. Union Geophys. Monogr. 100 (1997) 273-295.

[23] G.K. Czamanske, A.B. Gurevitch, V. Fedorenko, O. Simonov, Demise of the Siberian plume: paleogeographic and paleotectonic reconstruction from the prevolcanic and volcanic record, north-central Siberia, Int. Geol. Rev. 40 (1998) 95-115.

[24] L.T. Elkins-Tanton, B.H. Hager, Melt intrusion as a trigger for lithospheric foundering and the eruption of the Siberian flood basalts, Geophys. Res. Lett. 27 (2000) 3937-3940.

[25] M.J. Cintala, R.A.F. Grieve, The effects of differential scaling of impact melt and crater dimensions on lunar and terrestrial craters: Some brief examples, in: B.O. Dressler, R.A.F. Grieve, V.L. Sharpton (Eds.), Large Meteorite Impacts and Planetary Evolution, Geol. Soc. Am. Spec. Publ. 293 (1994) 51-59.

[26] D. Stoffler, A. Deutsch, M. Avermann, L. Bischoff, P. Brockmeyer, D. Buhl, R. Lakomy, V. Muller-Mohr, The formation of the Sudbury structure, Canada: toward a unified impact model, in: B.O. Dressler, R.A.F. Grieve, V.L. Sharpton (Eds.), Large Meteorite Impacts and Planetary Evolution, Geol. Soc. Am. Spec. Publ. 293 (1994) 303-318.

[27] J.D. O'Keefe, T.J. Ahrens, Planetary cratering mechanics, J. Geophys. Res. 98 (1993) 17011-17028.

[28] J.W. Swegle, Irreversible phase transitions and wave propagation in silicate materials, J. Appl. Sci. 68 (1995) 15631579.

[29] E. Pierazzo, A.M. Vickery, H.J. Melosh, A re-evaluation of impact melt production, Icarus 127 (1997) 408-423.

[30] M. Jull, D. McKenzie, The effect of deglaciation on mantle melting beneath Iceland, J. Geophys. Res. 101 (1996) 21815-21828.

[31] L. Slater, M. Jull, D. McKenzie, K. Gronvold, Deglaciation effects on mantle melting under Iceland: results from the northern zone, Earth Planet. Sci. Lett. 164 (1998) 151164.

[32] A.P. Jones, J.V. Smith, J.B. Dawson, E.C. Hansen, Metamorphism, partial melting, and K-metasomatism of garnet-scapolite-kyanite granulite xenoliths from Lashaine, Tanzania, J. Geol. 91 (1983) 143-165.
[33] F. Langenhorst, A. Deutsch, U. Hornemann, On the shock behaviour of calcite: Dynamic 85-GPa compression and multianvil decompression experiments, Meteorit. Planet. Sci. 33 (Suppl.) (1998) A90.

[34] D. McKenzie, M.J. Bickle, The volume and composition of melt generated by extension of the lithosphere, J. Petrol. 29 (1988) 625-679.

[35] P.J. Wyllie, Magmas and volatile components, Am. Mineral. 64 (1979) 469-500.

[36] J.P. Poirier, Physics of the Earth's Interior, Cambridge University Press, 2000, $312 \mathrm{pp}$.

[37] R.N. Thompson, S.A. Gibson, Transient high temperatures in mantle plume heads inferred from magnesian olivines in Phanerozoic picrites, Nature 407 (2000) 502-506.

[38] C.J. Hayhurst, R.A. Clegg, Cylindrically symmetric SPH simulations of hypervelocity impacts on thin plates, Int. J. Impact Eng. 20 (1997) 337-348.

[39] C.J. Hayhurst, H.J. Ranson, D.J. Gardner, N.K Birnbaum, Modelling microparticle hypervelocity oblique impacts on thick targets, Int. J. Impact Eng. 15 (1995) 375 386.

[40] E.M. Shoemaker, R.F. Wolfe, C.S. Shoemaker, Asteroid and comet flux in the neighbourhood of Earth, Geol. Soc. Am. Spec. Publ. 247 (1990) 155-170.

[41] J. Koulouris, P. Janle, B. Milkereit, S. Werner, Significance of large ocean impact craters, in: R. Gersonde, A. Deutsch (Eds.), Oceanic Impacts: Mechanisms and Environmental Perturbations, Ber. Polarforsch. 343 (1999) 4850.

[42] P.R. Weissman, Long-period Comets and the Oort Cloud, in: Near-Earth Objects, United Nations International Conference, Ann. N.Y. Acad. Sci. 822 (1997) 67-95.

[43] Report of the Task Force on Potentially Hazardous Near Earth Objects, British National Space Centre, 2000.

[44] M.M. Grady, R. Hutchinson, G.J. McCall, D.A. Rothery (Eds.), Meteorites: Flux with Time and Impact Effects, Geol. Soc. Spec. Publ. 140 (1998) 278 pp.

[45] I.H. Campbell, G.K. Czamanske, V.A. Fedorenko, R.I. Hill, V. Stepanov, Synchronism of the Siberian traps and the Permian-Triassic boundary, Science 256 (1992) 186193.

[46] G.J. Retallack, A. Seyedolali, E.S. Krull, W.T. Holser, C.P. Ambers, Search for evidence of impact at the Permian-Triassic boundary in Antarctica and Australia, Geology 26 (1998) 979-982.

[47] S.A. Bowring, D.H. Erwin, J.G. Jin, M.W. Martin, K. Davidek, W. Wang, U/Pb zircon geochronology and tempo of the end-Permian mass extinction, Science 280 (1998) 1039-1045.

[48] Y.G. Jin, Y. Wang, W. Wang, Q.H. Shang, C.Q. Cao, D.H. Erwin, Pattern of marine mass extinction near the Permian-Triassic boundary in South China, Science 289 (2000) 432-436.

[49] L. Becker, R.J. Poreda, A.G. Hunt, T.E. Bunch, M. Rampino, Impact event at the Permian-Triassic boundary: evidence from extraterrestrial noble gases in fullerenes, Science 291 (2001) 1530-1533. 
[50] L.W. Alvarez, W. Alvarez, F. Asaro, H.V. Michel, Extraterrestrial causes for the Cretaceous-Tertiary extinction, Science 208 (1980) 718-720.

[51] C.J. Hawkesworth, P.C. Lightfoot, V.A. Fedorenko, S. Blake, A.J. Naldrett, W. Doherty, N.S. Gorbachev, Magma differentiation and mineralisation in the Siberian continental flood basalts, Lithos 34 (1995) 61-88.

[52] B.V. Oleynikov, A.V. Okrugin, M.D. Tomshin et al., Native Metals Formation in Basic Rocks of the Siberian Platform, Yakut Branch of Soviet Academy of Sciences, Yakutsk (1985) 188 pp. (in Russian).

[53] Y.Y. Ryabov, G.N. Anoshin, Platinum-iron metallization in intrusive traps of the Siberian Platform, Geol. Geofiz. 40 (1999) 162-174 (in Russian).

[54] M.V. Gerasimov, Yu.P. Dikov, O.I. Yakovlev, F. Wlotzka, Reduction of iron during an impact, in: F. MartinezRuiz, M. Ortega-Huertas, I. Palomo (Eds.), Impact Markers in the Stratigraphic Record, Universidad de Granada, 2001, pp. 31-32.

[55] H. Klock, H.J. Palme, H.J. Tobschall, Trace elements in natural metallic iron from Disko Island, Greenland, Contrib. Mineral. Petrol. 93 (1986) 273-282.

[56] R.J. Walker, J.W. Morgan, E.S. Beary, M.I. Smoliar, G.K. Czamanske, M.F. Horan, Applications of the Pt-190-Os-186 isotope system to geochemistry and cosmochemistry, Geochim. Cosmochim. Acta 61 (1997) 4799 4807.

[57] S. Kravchenko, L.I. Schachotko, I.T. Rass, Moho discontinuity relief and the distribution of kimberlites and carbonatites in the northern Siberian Platform, Glob. Tecton. Metallog. 6 (1997) 137-140.

[58] W.D. Mooney, Crustal and upper mantle seismic velocity structure of the former USSR, 21st Seismic Research Symposium: Technologies for Monitoring the Comprehensive Nuclear-Test-Ban Treaty, US Dept. of Defence, 1999, pp. 162-171.

[59] M.K Reichow, A.D. Saunders, R.V. White, M.S. Pringle, A.I. Al'Mukhamedov, A.I. Medvedev, N.P. Kirda, ${ }^{40} \mathrm{Ar} /$ ${ }^{39} \mathrm{Ar}$ dates from west Siberian basin: Siberian flood basalt province doubled, Science 296 (2002) 1846-1849. 